\title{
TRANSCENDING SOCIAL MEDIA INTERACTIVITY TO THE SOCIAL COMMERCE ENVIRONMENT
}

Framarz Byramjee, Indiana University of Pennsylvania, Indiana, Pennsylvania, U.S.A. Parimal Bhagat, Indiana University of Pennsylvania, Indiana, Pennsylvania, U.S.A.

Pankaj Chaudhary, North Carolina A\&T State University, Greensboro, North Carolina, U.S.A. Jill Baumgardner, Indiana University of Pennsylvania, Indiana, Pennsylvania, U.S.A.

\author{
dx.doi.org/10.18374/JIBE-21-1.6
}

\begin{abstract}
This inquiry focuses on consumer interaction proclivities and assimilation initiatives amidst user interfacing along purchase driven buyer modes in online commerce environmental dynamics of the social media marketplace. Starting with a practitioner insight toward the prolificity of social media's penetration into the fabric of consumer commerce, the narrative delves into several social commerce determinants which manifest in affecting technology- and consumer-oriented facets of social channels' affinity for transactional and relational influences among consumers. The paper's objective works to establish a proposed social commerce framework for user intervention and adoption perspectives, by drawing upon consumer innovativeness, trustworthiness, and perceived value variables adapted from mobile commerce to social media channel dimensionality, and more critically configuring two new constructs applicable to social commerce i.e., consumers' personal connectivity and support within the social network, and consumers' working relation and presence within the social channel domain, for core inclusion in this newly formulated nomological model to figuratively analyze consumer's intention for value utility in social commerce. Direction for future research is then provided to posture empirical design and measurement prerogatives to follow.
\end{abstract}

Keywords: Social Media, Commerce, Technology, Interactivity, Transaction, Relationship, Value 